\title{
Assessment of the Engineering Conditions of Small Dams Using the Analytical Hierarchy Process
}

\author{
E. C. Shin ${ }^{1}$. D. H. Kim ${ }^{2}$ (D) J. K. Lee ${ }^{3}$ J. K. Kang ${ }^{1}$
}

Received: 3 January 2019 / Accepted: 15 August 2020 / Published online: 18 September 2020

(c) The Author(s) 2020

\begin{abstract}
Small dams managed by local governments in the Republic of Korea are facing operational difficulties owing to problems such as a decrease in the long-term storage capacity because of sedimentation and leakage, acceleration of aging, rapid lowering of water levels with seasonal rainfall and water usage, and the resulting deterioration of the overall integrity. However, the public demand for small dams has increased sharply for various purposes, especially flood and drought control. This paper presents a developed model for evaluating the condition of small dams using an analytic hierarchy process. Seventy-five earth dams in a province located in the eastern part of the Korean Peninsula were chosen. Three major components of dams, i.e., embankments, spillways, and water intake facilities, as well as the overall condition of the dam system, were evaluated. The usefulness of the improved model and its differences from the existing method were verified using the $t$-test. The improved model was found to be relatively simple and easy to apply in practice, and it enables on-time action for further treatment or reinforcement.
\end{abstract}

Keywords Analytic hierarchy process $\cdot$ Engineering conditions in small dams $\cdot$ Flood and drought control $\cdot t$-test

\section{Introduction}

Recently, cases of failure or collapse of small dams have been reported to be constantly increasing. It has been reported that dam failures are primarily related to leakage, piping, and overtopping due to heavy seasonal rainfalls (MIFAFF 2012). Reservoirs and dams in Korea are constructed per the relevant acts, i.e., act on dam construction and surrounding area support, and farming and fishing village maintenance act. There are over 17,000 dams that have multipurpose uses, such as municipal and industrial water, hydropower generation, flood control, and irrigation water. Of these, the majority of them, i.e., 17,531 or $99.5 \%$ of the reservoirs are used for agricultural purposes.

D. H. Kim

duhkim@naver.com

1 Department of Civil and Environmental Engineering, Incheon National University, Incheon, Republic of Korea

2 Plant Business Unit, Samsung C\&T Corporation, Seoul, Republic of Korea

3 Hydraulic Structure Division, Korea Infrastructure Safety Corporation, Ilsan, Republic of Korea
The International Commission on Large Dams (ICOLD) investigated the failure mechanism of dams and released the following series of reports based on their findings: "Lessons from Dam Incidents" (ICOLD 1974), "Deterioration of dams and reservoirs" (ICOLD 1983), and "Statistical Analysis on Dam Failures" (ICOLD 1995). Statistics reveal that most failures occurred at earth dams; however, the height of dams is not considered to be a critical factor or linked to the likelihood of dam failures (ICOLD 1995).

Recent studies have focused on developing a risk analysis model to effectively respond to any potential damages to dams at an early stage (ANCOLD 2003; ICOLD 2005; Bowles 2010). Many researchers have studied the influence factors using the analytic hierarchy process (AHP), which is a very flexible and simple method (Yasser et al. 2013; Dai 2016; Kaw and Manaf 2018).

The State of Oklahoma in the USA uses a checklist that includes more detailed items, classifying the inspection points into 14 major groups: general conditions, upstream slopes, crest, downstream slope of dams, abutment contacts, inlet structure, conduit and outlet, concrete spillway, auxiliary spillway, stilling basin, gates, instruments, development below the dam, and emergency action plan (OWRB 2010). It should be noted that the US practice lays more emphasis 
on the prevention of erosion and leakage at each part of the dam system. ICOLD (1995) listed 32 factors responsible for failures of "embankments" and 25 factors linked to failures of the "axillary structures" of dam systems. The failure modes are known to be mostly related to three major situations: overtopping, piping, and sliding. Sohler and Caldeira (2016) proposed a risk identification process for dams based on case histories and estimated probabilities of risk occurrences. A risk matrix was presented in terms of the probability and consequence with regard to the critical elements of each dam.

In Korea, the intensive annual rainfall during summer is known to be the most critical factor threatening the stability of earth dams. Such extreme rainfall often causes significant flooding and overflow of small dams, resulting in deterioration of the entire dam system. In particular, small dams are required for flood control to prevent water running-off from the hills and mountains during typhoons and rainy seasons. It is typical to have such small dams near cities in Korea, as the nation has mountains covering more than $70 \%$ of its land. Therefore, it is necessary to improve the efficiency of the evaluation process. Figure 1 illustrates a survey of the deterioration and slope protection types of 75 small dams in Korea.
This paper focuses on developing a model for assessing the engineering conditions of small dams using AHP. The improved model adopted and simplified the existing five-step process and enhanced its efficiency of inspection by reducing the evaluation processes to three major dam components.

\section{AHP Evaluation Model}

The analytic hierarchy process (Saaty 1980) is a technical process that determines the relative priority by a pairwise comparison matrix between the layered components. AHP is evaluated through stratification, pairwise comparison, weight calculation, and consistency verification. The most important step in applying the AHP process is layering.

In the first step, the decision-makers layer various interrelated decisions using stratification to determine the critical factors required for decision-making. Next, the pairwise comparison step compares the elements in the direct subordinate hierarchy, which are necessary for achieving the goal of the upper hierarchy, to create a matrix. For making a pair comparison matrix, the degree of contribution to the upper element is given by the 9-point scale method, as shown in Table 1.
Fig. 1 Survey for deterioration and slope protection of small dams in Korea
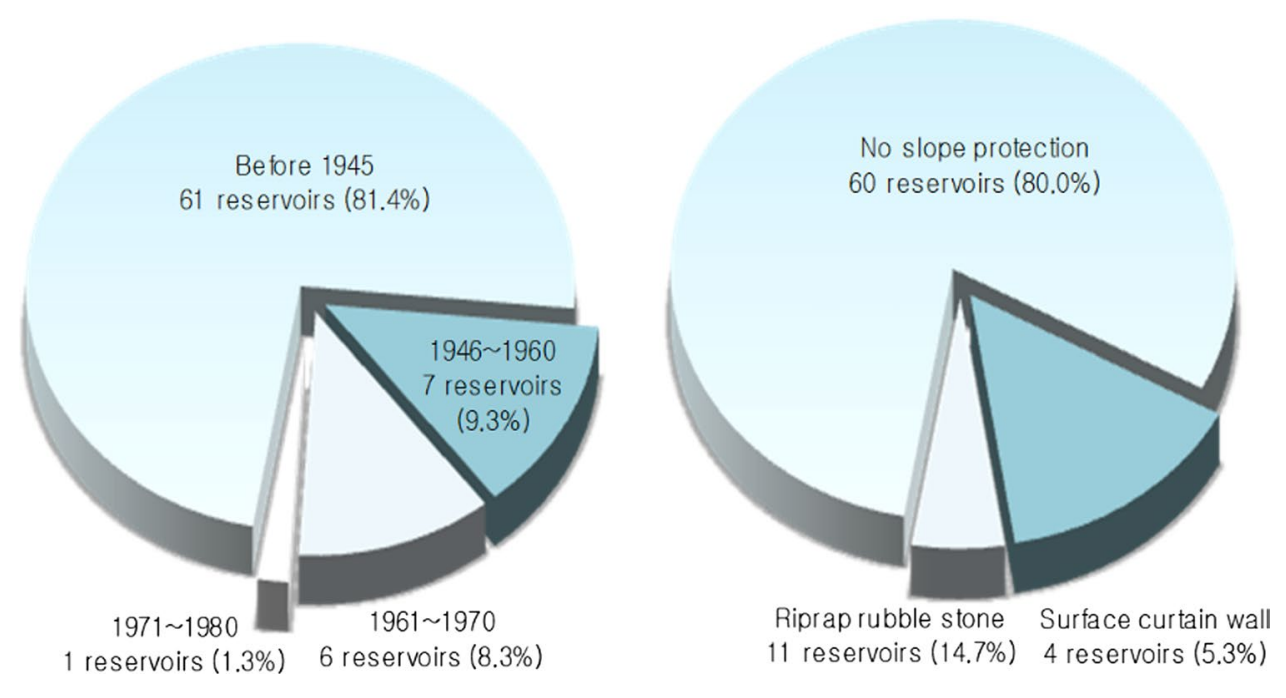

Table 1 Degree of contribution to the upper element

\begin{tabular}{lll}
\hline Intensity* & Definition & Explanation \\
\hline 1 & Equal & Two elements contribute equally to the objective \\
3 & Moderate & Experience and judgment slightly favor one element over another \\
5 & Strong & Experience and judgment strongly favor one element over another \\
7 & Very strong & One element is favored very strongly over another \\
9 & Extreme & One element over another; it is the highest possible order of affirmation \\
\hline
\end{tabular}

*Intensities of 2, 4, 6, and 8 can be used to express intermediate values, and intensities of 1.1, 1.2, 1.3, etc. can be used to separate elements further 
The numerical value obtained from the pairwise comparison matrix is small in the upper triangular part of the square matrix, and the lower triangular part is the reciprocal of its value. The diagonal of the matrix is 1 . When the decisionmaker performs a mutual comparison of the $n$ evaluation factors, with known relative weight in the hierarchy, a comparison matrix is obtained, as shown in Eq. (1):

$$
A=\left[a_{i j}\right]=\left[\begin{array}{ccccc}
1 & w_{1} / w_{2} & w_{1} / w_{3} & \cdots & w_{1} / w_{n} \\
w_{2} / w_{1} & 1 & w_{2} / w_{3} & \cdots & w_{2} / w_{n} \\
w_{3} / w_{1} & w_{3} / w_{2} & 1 & \cdots & w_{3} / w_{n} \\
\vdots & & & & \vdots \\
w_{n} / w_{1} & w_{n} / w_{2} & w_{n} / w_{3} & \cdots & 1
\end{array}\right]
$$

where $a_{i j}$ is an estimate of the relative weight; $w_{i} / w_{j}$ is the relative weight of $i$ with respect to element $j$. Matrix A is a reciprocal matrix in which the values of the diagonal elements are 1 .

Let the weight vector $v=\left[v_{1}, v_{2}, v_{3}, \cdots, v_{n}\right]$ be the relative importance vector to evaluate matrix A. Multiply $v^{\mathrm{T}}=\left[v_{1}, v_{2}, v_{3}, \cdots, v_{n}\right]^{\mathrm{T}}$ with $a_{i j}$ (matrix $A$ ) to obtain Eq. (2):

$A \cdot v^{\mathrm{T}}=\left[\begin{array}{ccccc}1 & w_{1} / w_{2} & w_{1} / w_{3} & \cdots & w_{1} / w_{n} \\ w_{2} / w_{1} & 1 & w_{2} / w_{3} & \cdots & w_{2} / w_{n} \\ w_{3} / w_{1} & w_{3} / w_{2} & 1 & \cdots & w_{3} / w_{n} \\ \vdots & & & & \vdots \\ w_{n} / w_{1} & w_{n} / w_{2} & w_{n} / w_{3} & \cdots & 1\end{array}\right]\left[\begin{array}{c}v_{1} \\ v_{2} \\ v_{3} \\ \vdots \\ v_{n}\end{array}\right]==\left[\begin{array}{c}n v_{1} \\ n v_{2} \\ n v_{3} \\ \vdots \\ n v_{n}\end{array}\right]=n \cdot v$

where $n$ is the maximum eigenvalue of $A$ or the number of columns.

Equation (2) is an eigenvalue problem for obtaining a nonzero solution in $n$ simultaneous systems of equations. The weight vector $v$ is as shown in Eq. (3):

$A \cdot v=\lambda \cdot v$

where $v$ is a weight vector representing the relative importance of the elements, as an eigenvector $([A-n I] \cdot v=0)$, and $\lambda$ is the eigenvalue.

The estimate $a_{i j}$ that shows the relative importance of element $i$ with respect to $j$, which is the subject of pairwise comparisons, can be defined as Eq. (4):

$a_{i j}=\left(1+\delta_{i j}\right) \frac{w_{i}}{w_{j}}$

where $\delta_{i j}$ represents the degree of discrepancy and has a value of -1 or higher.

The difference between the estimated and defined maximum eigenvalues, $\lambda_{\max }$ and $n$, respectively, of the pairwise comparison matrix is given by Eq. (5):

$\lambda_{\max }=\frac{1}{k} \sum_{1 \leq i<j \leq k} \frac{\delta_{i j}^{2}}{1+\delta_{i j}} \geq n$
Because the values obtained from the pairwise comparisons are compared only with the values of the two items, the overall consistency ratio (C.R.) given by Eq. (6) should be investigated.

C.R. $=\frac{\text { C.I. }}{\text { R.I. }}$

where C.I. is the consistency index $\left(=\mu=\frac{\lambda_{\max }-n}{n-1}\right)$ and R.I. is the random index.

C.R. is 0 when the matrix has a perfect consistency, and the higher the number, the more inconsistent it is. It is known that if the consistency ratio is less than 0.1 , then the judgment of the evaluators is reasonable, and if the ratio is less than 0.2 , it is acceptable.

\section{Survey and Field Inspection}

\subsection{Survey Program}

As part of the framework to develop the model, a survey was conducted to collect opinions from a group of experts with relevant experiences. A total of 400 members were nominated to participate in the survey regarding the critical factors that most likely affect the stability of small dams. The occupancy of the participants varied from design, construction, inspection, management, and planning. A total of 230 (57.5\% return ratio) answer sheets and records of interviews were completed. Amongst the 148 respondents' answer sheets chosen for this study, consistency ratio was measured to be less than 0.1 . Table 2 shows the participants of the survey program.

Table 2 Participants of the survey program

\begin{tabular}{llll}
\hline Distribution of respondents & $\begin{array}{l}\text { Number of } \\
\text { respondents* }\end{array}$ & Ratio (\%) \\
\hline Specialty & Water resources & 62 & 41.9 \\
& Geotechnical & 50 & 33.8 \\
& Construction safety & 20 & 13.5 \\
& Structural & 16 & 10.8 \\
Occupancy & Inspection & 78 & 52.7 \\
& Management & 36 & 24.3 \\
& Design & 26 & 17.6 \\
& Maintenance & 8 & 5.4 \\
Career & Less than 5 years & 38 & 25.7 \\
& Less than 10 years & 46 & 31.1 \\
& Less than 20 years & 38 & 25.7 \\
& Over 20 years & 26 & 17.5 \\
\hline
\end{tabular}

*Total number of participants in the survey is 148 


\subsection{Field Inspection in Embankments}

Seventy-five earth dams in a province in Korea were inspected, and the results are summarized. All the dams were categorized into small dams per the ICOLD criteria (2011), with most of them having a height less than $10 \mathrm{~m}$ and a storage capacity less than 300,000 tons. About $60 \%$ of the dams were known to have been built before the 1960s.

Sixty $(80.0 \%)$ of the small dams were found to have no surface protection on downhill slopes. Only eleven (14.6\%) had rip-rap or gavel covers for protection that were built at the time of construction. Four other dams (5.3\%) had different surface protections installed for repair after construction. Only seven dams $(9.3 \%)$ had separate spillways from the embankments. Most dams were found to have been exposed to various damages and defects such as vegetation, crack and deformation, leakage, settlement, movement of slopes, and erosion. The percentage of damage and their degree varied from item-to-item. Leakage and erosion were found to be the most serious issues. Leakage dams were observed at sixtysix dams (88.0\%); forty-two dams had leakage at the toes of the downstream slopes, ten dams at the abutment contacts, seven dams at spillway abutments, and seven dams at outlet conduit abutments. Leakage was found at twenty-six dams $(34.6 \%)$ with seepage paths generated through the embankments, showing wet downstream slope surfaces.

\subsection{Field Inspection in Spillways and Water Intake Facilities}

Most of the dams have channels without separate spillways. Of the 75 dams that were investigated, 54 dams (72.0\%) had open channels, and 18 dams $(24.0 \%)$ had closed channels. Sixty-four percent of the spillways were made of concrete, and the others were built of soils and rocks. Damages and defects found in the spillways included cracks, displacements, failure of concrete, and exposed rebar of the structures. Deterioration and aging have occurred significantly in 24 dams (32.0\%), and ten (13.3\%) of them had lost their function of water flow.

Two types of water intake structures were found to be used for the dams: (1) screw type at 57 dams (76.0\%) and (2) wood-pile type at 18 dams (24.0\%). Damages and defects at intake facilities included corrosion, deformation, cracking of the concrete, and resulting leakage and migration of soils into the facilities. Serious deterioration of the facilities, which required immediate repair, was found at four dams. Another eleven dams (14.7\%) were found to have already lost water intake functions. The characterization of existing spillways is shown in Fig. 2.

\section{Results of the AHP-Based Model}

\subsection{Comparison of Estimation}

The assessment criteria for dam conditions, which were modified by the Ministry of Land, Transportation, and Maritime Affairs (2011) of Korea, are shown in Table 3. The descriptions corresponding to each condition were simplified and clarified. Dam conditions, such as damage and defects, are scored in the increasing order of defects from 0 to 100 and designated into five categories $[\mathrm{A}]$ to $[\mathrm{E}]$, respectively. If the resulting condition was $[\mathrm{A}]$ or $[\mathrm{B}]$, immediate action is not required, except for partial repair. If the scores fall in conditions [D] or [E], restrictions affect the use of dam facilities, and immediate treatment and reinforcement are required.

The AHP-based model process includes five steps. First, relevant data are collected for the preliminary study. The records during the dam construction and the histories of maintenance and repair thereafter are the main elements to
Fig. 2 Characterization of existing spillways

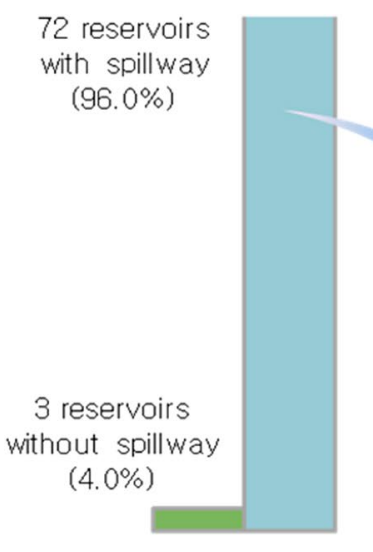

Presence of spillway

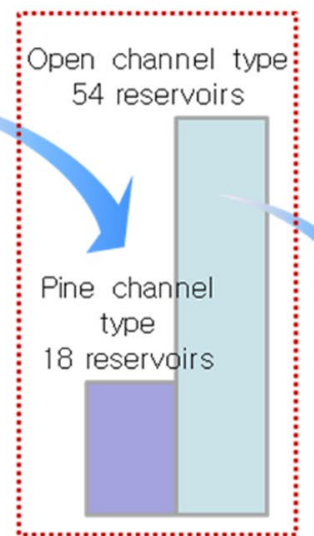

Spillway type

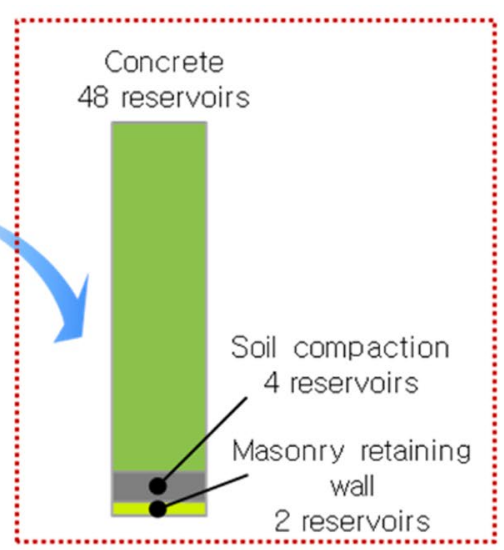

Classification of open channel type reservoirs by used material 
Table 3 Assessment criteria for the dam condition (MLTMA 2011)

\begin{tabular}{lll}
\hline Condition & Score & Description \\
\hline [A] & $0 \leq S \leq 7.5$ & No treatment is required \\
[B] & $7.5<S \leq 20$ & Partial repair is required to obtain durability \\
[C] & $20<S \leq 32.5$ & Repair is required to prevent loss of durability and functions at the main parts \\
[D] & $32.5<S \leq 45.0$ & $\begin{array}{c}\text { Immediate restriction is required for usage, and immediate repair is required as defects are observed at the main } \\
\text { parts } \\
\text { IE] }\end{array}$ \\
& $S>45.0$ & $\begin{array}{c}\text { Immediate restriction is required for usage. The main members could face serious issues such as collapse. Imme- } \\
\text { diate treatment and reinforcement are required }\end{array}$ \\
\hline
\end{tabular}

track to ensure the dams' stability and to predict their behavior in the future. Second, an in situ survey and inspection are planned and performed to accumulate data required for rating the dam conditions. Both qualitative and quantitative measurements are required for a complete inspection. The quality of the measurement is the most critical factor in determining the reliability of the entire inspection program. Third, the dam condition is evaluated for the major components: embankments, spillways, and water intake facilities, where the scoring systems are adjusted proportionally if any non-applicable items, which are marked as $\square$ in Table 4, exist and adjustment is required. Fourth, a comprehensive assessment is made reflecting the priorities based on the mean weight of each criterion. Fifth, further actions are executed per the judgment and decisions made by relevant experts.

\subsection{Evaluation of Structural and Engineering Conditions}

The checklist aims to quantitatively evaluate the structural and engineering conditions of embankments, spillways, and water intake facilities. Each main item in the table includes elements of facilities with different ratings. Scores are evaluated by cumulating the ratings with different weights. The table indicates that the occurrence of cracks, displacement, or sliding are the most important items for checking the stability of embankments. For spillways, the existence of obstructions at either open or closed channels is the most likely element to determine the serviceability of the dam system, affecting their long-term stability. Controlling leakage and seepage was found to be the most important target to inspect to ensure the functioning of water intake facilities.

\section{Review of the AHP-Based Model}

\subsection{Comparison of Existing and AHP-Based Models}

A comparison of the evaluation using the AHP and existing methods is summarized in Table 5. For embankments, the results are similar between the existing and improved models. A significant number of spillways and water intake facilities were rated lower with the improved model. In addition, the transition of conditions from [A] or [B] into $[\mathrm{C}]$ means that immediate repair is required to prevent further loss of durability and functionality of the dams. The overall evaluation of dams was found to be similar to those performed with the existing model. Such results are due to the low weighting given to spillways (0.24) and water intake facilities $(0.14)$ compared to that of embankments (0.62).

The distribution of data estimated with the existing and AHP-based models is illustrated in Fig. 3. It is observed that most ratings estimated by the AHP model are higher than those measured by the existing model for the spillways and water intake facilities. The evaluation of the overall condition was similar in both the methods, and the correlation was 0.684 .

\subsection{Statistical Review of AHP-Based Model}

A series of t-tests were conducted to measure the level of differences in the results estimated using the existing and AHP-based models. Independent sample t-tests were applied to the estimates, and the results are summarized in Table 6. The results from the two models have similar mean values for embankments and the $t$-test resulted in far lower values than the critical value of 2.000 , corresponding to a $p$-value less than 0.05. Therefore, we conclude that the two models have similarities with limited differences.

For the cases of spillways and water intake facilities, the $t$-values were measured to be -5.647 and -4.543 . As the significance probability was 0.000 , based on the significance level of 0.05 , significant differences were exhibited in the estimates between the two models.

The identification of dams at potential risk is one of the first steps in dam management. Preparing for a scenario of small dam failure has hardly received any attention. Such preparations should be made in conjunction with a repair program. 
Table 4 Evaluation of embankments, spillways, and water intake facilities

\begin{tabular}{|c|c|c|c|c|c|c|c|}
\hline \multirow[t]{2}{*}{ Items per facility } & \multirow[t]{2}{*}{ Score } & \multicolumn{5}{|c|}{ Rating } & \multirow[t]{2}{*}{ Weight (\%) } \\
\hline & & [a] & [b] & [c] & {$[\mathrm{d}]$} & [e] & \\
\hline A. Embankment* & 100 & \multicolumn{5}{|c|}{ Sum of $(1,2,3$, and 4$)$} & 61.91 \\
\hline 1. Crest & 17.5 & \multicolumn{5}{|c|}{ Sum of (1), (2), (3), and (4) } & 10.79 \\
\hline (1) Cracks & & 0 & 1.5 & 3.5 & 5.0 & 6.5 & 4.05 \\
\hline (2) Settlement & & 0 & 1.5 & 2.5 & 4.0 & 5.0 & 3.07 \\
\hline (3) Erosion & & 0 & 1.0 & 2.0 & 2.5 & 3.5 & 2.10 \\
\hline (4) Vegetation & & 0 & 0.5 & 1.5 & 2.0 & 2.5 & 1.57 \\
\hline 2. Upstream slope & 26.0 & \multicolumn{5}{|c|}{ Sum of (1), (2), (3), (4), (5) and (6) } & 16.05 \\
\hline (1) Cracks & & 0 & 1.0 & 2.5 & 3.5 & 4.5 & 2.75 \\
\hline (2) Settlement & & 0 & 1.0 & 2.5 & 3.5 & 4.5 & 2.70 \\
\hline (3) Erosion & & 0 & 1.5 & 2.5 & 4.0 & 5.0 & 3.00 \\
\hline (4) Slope & & 0 & 1.0 & 1.5 & 2.5 & 3.0 & 1.97 \\
\hline (5) Sliding & & 0 & 1.5 & 3.5 & 5.0 & 6.0 & 3.96 \\
\hline (6) Vegetation & & 0 & 1.0 & 1.5 & 2.5 & 3.0 & 1.67 \\
\hline 3. Downstream slope and toe & 26.5 & \multicolumn{5}{|c|}{ Sum of (1), (2), (3), (4), (5), and (6) } & 16.46 \\
\hline (1) Cracks & & 0 & 1.5 & 2.5 & 4.0 & 5.0 & 3.03 \\
\hline (2) Settlement & & 0 & 1.0 & 2.5 & 3.5 & 4.5 & 2.78 \\
\hline (3) Erosion & & 0 & 1.0 & 2.0 & 3.0 & 4.0 & 2.57 \\
\hline (4) Slope end protection & & 0 & 1.0 & 1.5 & 2.5 & 3.0 & 2.01 \\
\hline (5) Sliding & & 0 & 1.5 & 3.5 & 5.0 & 7.0 & 4.16 \\
\hline (6) Vegetation & & 0 & 1.0 & 1.5 & 2.5 & 3.0 & 1.91 \\
\hline 4. Seepage and leakage & 30.0 & \multicolumn{5}{|c|}{ Score of (1) } & 18.61 \\
\hline (1) Seepage and/or leakage & & 0 & 7.5 & 15.0 & 22.5 & 30.0 & 18.61 \\
\hline B. Spillway & 100 & \multicolumn{5}{|c|}{ Sum of $(1,2$, and 3$)$} & 23.90 \\
\hline 1. Channel (choose one of $\mathrm{a}, \mathrm{b}$, or $\mathrm{c}$ ) & 47.5 & & & & & & \\
\hline$\square^{\mathrm{a}}$ a. Open channel (Earthen) & & \multicolumn{5}{|c|}{ Sum of (1) and (2) } & 11.40 \\
\hline (1) Obstructions & & 0 & 3.5 & 7.0 & 10.5 & 14.0 & 3.39 \\
\hline (2) Erosion & & 0 & 8.5 & 17.0 & 25.0 & 33.5 & 8.01 \\
\hline$\square \mathrm{b}$. Open channel (Concrete) & & \multicolumn{5}{|c|}{ Sum of (1), (2), (3) and (4) } & 11.40 \\
\hline (1) Obstructions & & 0 & 3.5 & 7.0 & 10.5 & 14.0 & 3.30 \\
\hline (2) Condition of side wall & & 0 & 3.5 & 6.5 & 10.0 & 13.0 & 3.19 \\
\hline (3) Condition of floor & & 0 & 2.5 & 5.0 & 7.5 & 10.0 & 2.35 \\
\hline (4) Seepage and/or leakage & & 0 & 2.5 & 5.5 & 8.0 & 10.5 & 2.56 \\
\hline$\square$ c. Closed channel & & \multicolumn{5}{|c|}{ Sum of (1), (2), and (3) } & 11.40 \\
\hline (1) Obstructions & & 0 & 5.0 & 10.0 & 14.5 & 19.5 & 4.68 \\
\hline (2) Condition of discharge pipe & & 0 & 3.0 & 6.5 & 9.5 & 12.5 & 3.02 \\
\hline (3) Seepage and leakage in discharge pipe & & 0 & 4.0 & 8.0 & 11.5 & 15.5 & 3.70 \\
\hline$\square 2$. Control section with gates & 47.5 & \multicolumn{5}{|c|}{ Sum of (1), (2), (3) } & 11.34 \\
\hline (1) Control to operate & & 0 & 0 & 0 & 0 & 20.0 & 4.78 \\
\hline (2) Condition of water control devices & & 0 & 3.5 & 7.0 & 10.5 & 14.0 & 3.34 \\
\hline (3) Condition of concrete structures & & 0 & 3.5 & 7.0 & 10.0 & 13.5 & 3.22 \\
\hline$\square 3$. Access bridge & 5.0 & \multicolumn{5}{|c|}{ Score of (1) } & 1.16 \\
\hline (1) Condition of access bridge & & 0 & 1.5 & 2.5 & 4.0 & 5.0 & 1.16 \\
\hline$\square$ C. Water intake facilities & 100 & \multicolumn{6}{|c|}{14.19} \\
\hline 1. Intake structures & 39.0 & \multicolumn{5}{|c|}{ Sum of (1), (2), (3), and (4) } & 5.52 \\
\hline (1) Control to operate & & 0 & - & - & - & 15.5 & 2.17 \\
\hline (2) Condition of water control devices & & 0 & 3.0 & 5.5 & 8.5 & 11.0 & 1.58 \\
\hline (3) Condition of intake/control structures & & 0 & 2.5 & 4.5 & 7.0 & 9.0 & 1.25 \\
\hline$\square(4$ Condition of walkway & & 0 & 1.0 & 2.0 & 2.5 & 3.5 & 0.52 \\
\hline 2. Outlet structures & 61.0 & \multicolumn{5}{|c|}{ Sum of (1), (2), and (3) } & 8.67 \\
\hline (1) Condition of outlet pipe & & 0 & 7.0 & 14.0 & 20.5 & 27.5 & 3.91 \\
\hline
\end{tabular}


Table 4 (continued)

\begin{tabular}{lllllllll}
\hline Items per facility & Score & \multicolumn{2}{l}{ Rating } & & \multicolumn{3}{l}{ Weight (\%) } \\
\cline { 3 - 6 } & & {$[\mathrm{a}]$} & {$[\mathrm{b}]$} & {$[\mathrm{c}]$} & {$[\mathrm{d}]$} & {$[\mathrm{e}]$} & \\
\hline (2) Seepage and leakage in outlet pipe & 0 & 7.0 & 14.5 & 21.5 & 28.5 & 4.03 \\
3) Condition of outlet channel & 0 & 1.5 & 2.5 & 4.0 & 5.0 & 0.73 \\
\hline
\end{tabular}

${ }^{a} \square$ : Judging selection whether it is installed from the configuration characteristics of the reservoir and dam *Ratings of [a] and [e] denote the best and the worst conditions, respectively;

Table 5 Comparison of evaluation using the AHP and existing methods

\begin{tabular}{llllll}
\hline Facility & Model & Number of samples & \multicolumn{2}{l}{ Condition } & \\
\cline { 5 - 6 } & & & {$[\mathrm{A}]$ and $[\mathrm{B}]$} & {$[\mathrm{C}]$} & {$[\mathrm{D}]$ and $[\mathrm{E}]$} \\
\hline Embankment & Existing & 75 & 29 & 28 & 18 \\
& AHP & 75 & 29 & 25 & 21 \\
Spillway & Existing & 75 & 54 & 18 & 3 \\
& AHP & 75 & 26 & 35 & 14 \\
Water intake & Existing & 69 & 52 & 7 & 10 \\
& AHP & 69 & 13 & 44 & 12 \\
Overall condition & Existing & 75 & 26 & 35 & 14 \\
& AHP & 75 & 23 & 32 & 20 \\
\hline
\end{tabular}

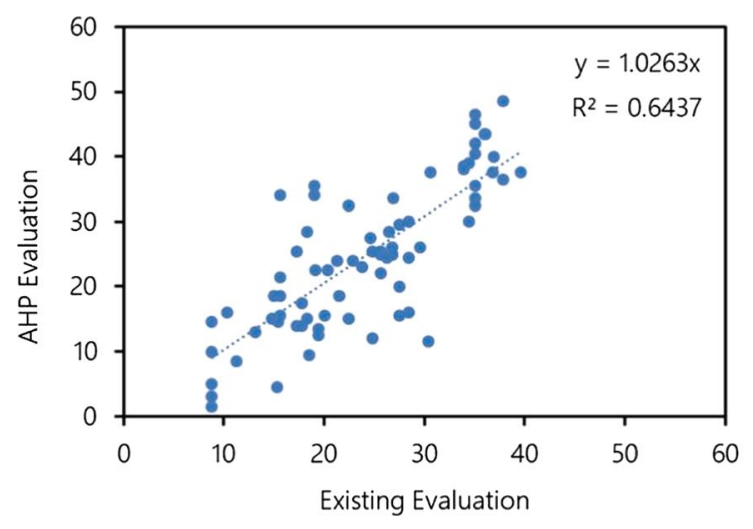

(a) Embankment

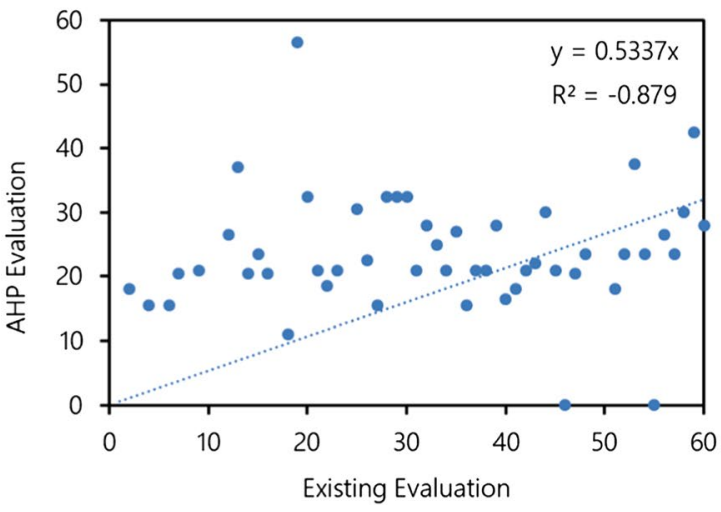

(c) Water Intake Facility

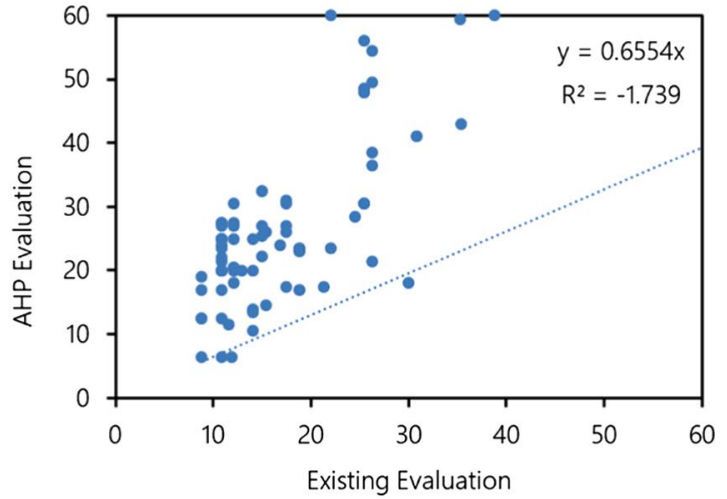

(b) Spillway

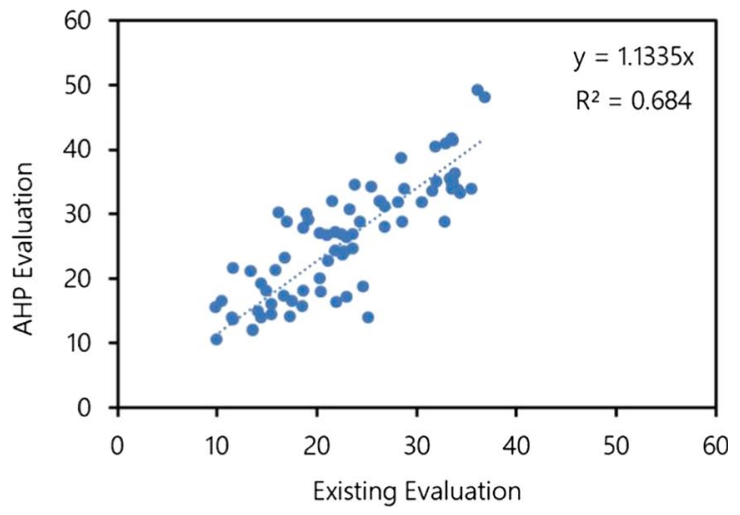

(d) Overall Condition

Fig. 3 Comparison of dam conditions measured by existing and AHP-based models 
Table 6 Results of $t$-test for the independent sample

\begin{tabular}{|c|c|c|c|c|c|c|c|c|}
\hline \multirow[t]{2}{*}{ Facility } & \multirow[t]{2}{*}{ Model } & \multirow[t]{2}{*}{ Nom } & \multirow[t]{2}{*}{ Mean } & \multirow{2}{*}{$\begin{array}{l}\text { Standard } \\
\text { deviation }\end{array}$} & \multirow{2}{*}{$\begin{array}{l}\text { Standard error } \\
\text { mean }\end{array}$} & \multicolumn{3}{|c|}{$t$-test for equality of means } \\
\hline & & & & & & $\bar{t}$ & $\mathrm{DF}^{\mathrm{a}}$ & $\mathrm{Sig}^{\mathrm{b}}$ \\
\hline \multirow[t]{2}{*}{ Embankment } & Existing & 75 & 24.135 & 8.566 & 0.989 & -0.316 & 148 & 0.753 \\
\hline & Improved & 75 & 24.653 & 11.364 & 1.312 & & & \\
\hline \multirow[t]{2}{*}{ Spillway } & Existing & 75 & 16.825 & 7.229 & 0.835 & $-5.647^{* * *}$ & 148 & 0.000 \\
\hline & Improved & 75 & 26.836 & 13.543 & 1.564 & & & \\
\hline \multirow[t]{2}{*}{ Water intake } & Existing & 69 & 18.477 & 11.290 & 1.359 & $-4.543^{* * *}$ & 136 & 0.000 \\
\hline & Improved & 69 & 28.703 & 14.748 & 1.775 & & & \\
\hline \multirow[t]{2}{*}{ Overall condition } & Existing & 75 & 23.125 & 7.452 & 0.860 & -1.929 & 148 & 0.056 \\
\hline & Improved & 75 & 26.521 & 8.960 & 1.035 & & & \\
\hline
\end{tabular}

${ }^{\mathrm{a}} \mathrm{DF}$ : degree of freedom, ${ }^{\mathrm{b}} \mathrm{Sig}$ : significance, ${ }^{*} P<0.05, * * P<0.01, * * * P<0.001$

\section{Conclusions}

This study presented a developed model for evaluating the engineering conditions of small dams using an analytical hierarchy process. A series of surveys were conducted to collect and analyze the opinions of experts with relevant experiences and expertise on inspection and maintenance of dams. The improved model adopted and simplified the existing five-step process and enhanced its efficiency of inspection by reducing the order of evaluation processes from four or six to only two.

Three major components were selected as the target elements to rate the dam conditions: embankments, spillways, and water intake facilities. Embankments had the highest weight rating of $61.91 \%$, as it dominates the overall stability of dams, followed by spillways and water intake facilities. The final ratings for the embankments assessed using the existing and improved models were similar, while the conditions of spillways and water intake facilities were evaluated lower, especially the worst conditions, when using the AHPbased model in the $t$-test.

The significantly simplified process by AHP and a concise checklist of the improved model are expected to enable practical application in the maintenance of small dams and on-time action for treatment and reinforcement as needed. The improved method, as the importance of each item of the dam facilities is reflected for inspection, is regarded as more realistic and practical for representing the actual field conditions.

However, small-scale dams lack adequate budget investment over long periods of public use. Therefore, it is necessary to accurately reflect the level of risk assessment and the impairment factors that occur in the future. In addition, it is also necessary to develop a model that can evaluate reinforcement plans and investment priorities through continuous development. In future research, the AHP evaluation model developed in this study is expected to provide the foundation for preventing the destruction of small reservoirs and dams in advance and for maintaining dam function as a reliable facility.
Acknowledgements This study was supported by the Incheon National University Research Grant in 2014.

Open Access This article is licensed under a Creative Commons Attribution 4.0 International License, which permits use, sharing, adaptation, distribution and reproduction in any medium or format, as long as you give appropriate credit to the original author(s) and the source, provide a link to the Creative Commons licence, and indicate if changes were made. The images or other third party material in this article are included in the article's Creative Commons licence, unless indicated otherwise in a credit line to the material. If material is not included in the article's Creative Commons licence and your intended use is not permitted by statutory regulation or exceeds the permitted use, you will need to obtain permission directly from the copyright holder. To view a copy of this licence, visit http://creativecommons.org/licenses/by/4.0/.

\section{References}

ANCOLD (2003) Guidelines on risk assessment. Australian National Committee on Large Dams, Sydney, New South Wales, Australia

Bowles DS (2010) Risk assessment in dam safety decision making. Invited Paper Proc United Eng Found Conf Risk-Based DecisMaking Water Resour 11:161-166

Dai X (2016) Dam site selection using an integrated method of AHP and GIS for decision making support in Bortala, Northwest China. Master of Science thesis, Lund University

ICOLD (1974) Lessons from dam incidents. International Commission on Large Dams, Paris, France

ICOLD (1983) Deterioration of dams and reservoirs. International Commission on Large Dams, LNEC, Lisboa, Portugal

ICOLD (1995) Dam failures-statistical analysis. International Commission on Large Dams Bulletin 99, Paris, France

ICOLD (2005) Risk assessment in dam safety management-A reconnaissance of benefits, methods and current applications. Int Comm Large Dams Bull 130:276

ICOLD (2011) Small dams; design, surveillance and rehabilitation. Int Comm Large Dams Draft Bull 13-16

Kaw KM, Manaf LA (2018) Integration of Delphi technique and analytical hierarchy process in selecting the type of dam: a case study of Bungoh catchment in Sarawak, Malaysia. Int J Anal Hierarchy Proc 10(1):20-38. https://doi.org/10.13033/ijahp.v10i1.493

MIFAFF (2012) Statistical yearbook of land and water development for agriculture (in Korean), Ministry of Food, Agriculture, Forestry, and Fisheries, Korea

MLTMA (2011) Guidelines for dam inspection (in Korean). Ministry of Land, Transport and Maritime Affairs, Korea 
OWRB (2010) Dam inspection guidelines. Dam Safety Fact Sheet Oklahoma Water Resources Board, Oklahoma. https://www.owrb. ok.gov/damsafety/pdf/DamInspectionGuidelines.pdf

Saaty TL (1980) The analytical hierarchy process: planning, priority setting, resource allocation. McGraw-Hill, New York

Sohler FAS, Caldeira LMMS (2016) Safety of dams-a pathological approach of qualitative and quantitative risks. J Civ Eng Architect 10:1032-1051. https://doi.org/10.17265/1934-7359/2016.09.007
Yasser M, Jahangir K, Mohmmad A (2013) Earth dam site selection using the analytic hierarchy process (AHP): a case study in the west of Iran. Arab J Geosci 6:3417-3426. https://doi.org/10.1007/ s12517-012-0602-x 